\title{
Teaching Methods, Approaches and Strategies used in EFL Classrooms in English Language Centers and Schools of Mahabad
}

\section{Asst. Lec. Khadija Muhammad Abdullah}

Accounting Dep. Lebanese French University-Erbil-Iraq zhinakhoshmanesh@lfu.edu.krd

\section{ARTICLE INFO}

\section{Article History:}

Received: 13/5/2018

Accepted: 25/6/2018

Published: Fall 2018

Doi:

10.25212/Ifu.qzj.3.4.1

Keywords:

English teaching, teaching approaches, teaching strategies, communicative language teaching

\section{ABSTRACT}

The qualitative research goals are to investigate the EFL teaching methods, approaches and strategies which are used in English as a foreign language classes in Mahabad. Qualitative research methods, observations and interviews were administered with 8 English teachers to obtain the data from schools and English Language Centers in Mahabad. The results of the study regarding senior high schools revealed that Grammar Translation Method (GTM) and the Audio-lingual Method (ALM) were used dominantly in the English classes. Concerning English Language Centers in Mahabad, the Audiolingual Method (ALM) and the Communicative Language Teaching (CLT) were the dominant methods applied in English classes. Being compared with senior students of the high schools, the activities and strategies used in the Centers helped students to use the language and communicate and the teachers were also more friendly and adaptable. Besides, they were able to use a variety of activities. While the teachers from schools placed emphasis on rote learning of word lists and explaining grammar 


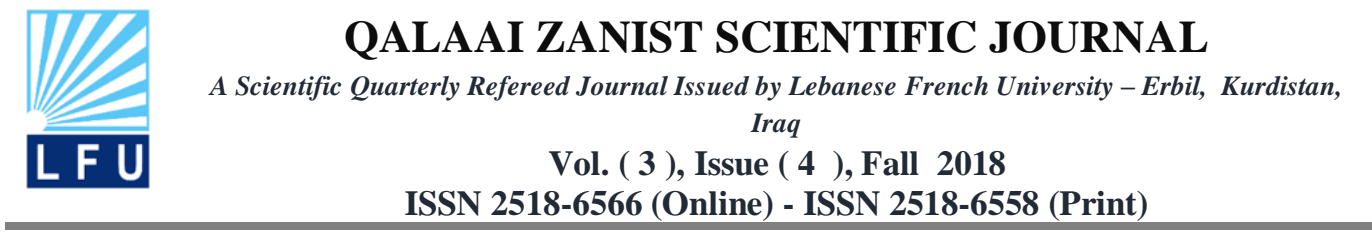

elaborately. New lexical and grammatical items in English were explained in Kurdish.

\section{Introduction}

Nowadays, teaching of English as a Foreign Language (TEFL) or a Second Language (TESOL) is of paramount importance all over the world. Students and learners spend huge amounts of time to learn English in order to communicate with people around the world. Furthermore, English has become a very important means for academic achievement.

Teaching English as a foreign language is a challenging task in Iran. Considerable attention has been paid to English in our country. As a result, English has been included in the curriculum of Iranian schools and universities for several reasons. The first reason is that most of latest scientific and technological resources are written in English, thus, they need an efficient amount of proficiency in English language. Second, the efficient use of the Internet demands learning English. Third, Knowing English lead to cultural exchange among nations.

Students in Iran study English for seven years in school. It starts at the age of 11 , at $6^{\text {th }}$ grade in schools and it carries on up to university. However, students are not successful in learning English. Consequently, researchers have tried to investigate the reasons why Iranian students cannot interact with other people in the real contexts, and what methods and strategies their teachers apply for this goal. Behroozi and Amoozegar (2014)'s paper refers to the necessity of reassessing the approaches used to teach English language in Iran. The collected data showed that Iranian students after nearly seven years of education neither are able to speak fluently in English nor communicate in English because they are aware with their grammar mistakes. Akbari (2015) studied about the reasons for a lack of students' proficiency after studying English language at high schools of Iran for seven years. In fact, they cannot use English for communication. Her findings illustrates that factors behind the failure of the students are materials, teachers, teaching methods, students, evaluation, policy and curriculum.

In their paper, Ashari and Zarrin (2014) tried to examine the problems concerning the failure of Communicative Language Teaching in schools of Iran and find some solutions for those issues. The major problem was that this approach is not compatible with Iranian cultural values, students' needs and motivation. The 


\section{QALAAI ZANIST SCIENTIFIC JOURNAL \\ A Scientific Quarterly Refereed Journal Issued by Lebanese French University - Erbil, Kurdistan, Iraq \\ L F U Vol. ( 3 ), Issue ( 4 ), Fall 2018 \\ ISSN 2518-6566 (Online) - ISSN 2518-6558 (Print)}

findings revealed that educational system has been strongly influenced by politics. Besides, policy constrained the authors' choices and this, in turn, has led to limited freedom of teachers in their teaching. They suggested a change in curriculum, textbooks, learning and teaching strategies and activities to implement this approach to help students to use English language in communication.

Regarding the fact that teaching can have effects on students learning, approaches and methods used by teachers is one of the factors which shows their teaching qualities. This paper focuses on language teaching and learning approaches and methods applied in Mahabad schools and English Language Centers based on "Approaches and Methods in Language Teaching" by Jack Richards and Richards(1989) and "Methods and Approaches in Language Teaching in Brief" by Boran (2010). These approaches and methods are: the Grammar Translation Method, Situational Language Teaching, the Audio-Lingual Method, Suggestopedia, Communicative Language Teaching, the Total Physical Response Method, the Silent Way, Community Language Learning, and the Total Physical Response Method.

\section{Research Question}

The study try to answer the following question: Which teaching methods, approaches, and strategies were applied in English Language Centers and high schools for teaching English in Mahabad?

\section{Literature Review}

Looking for the best ways of teaching language have been existed for a long time in the history of language teaching. For more than a century, discussion, and debate have often been on issues like the development of fluency and accuracy in teaching, the grammar role in the language curriculum, the role of lexical items in language learning, choosing syllabus frameworks in designing courses, the role of technology and materials, effective learning strategies, motivating learners, learning and memorization, theory learning and their use in teaching, teaching receptive and productive skills and techniques required for teaching the four skills within the teaching profession. Approaches and Methods in Language Teaching ( Richards, 1989) and (Boran, 2010) are explained as follows:

Grammar-translation Method: In this method, teachers translate to first language. Students should memorize long lists of lexical items and grammar rules. 


\section{QALAAI ZANIST SCIENTIFIC JOURNAL \\ A Scientific Quarterly Refereed Journal Issued by Lebanese French University - Erbil, Kurdistan, Iraq \\ L F U Vol. ( 3 ), Issue ( 4 ), Fall 2018 \\ ISSN 2518-6566 (Online) - ISSN 2518-6558 (Print)}

Furthermore, speaking is less or not emphasized (Willis, 1990). Learning language is done by using deductive approach. First, the teacher gives the general rule of grammar explicitly, and then asks students to apply it to other examples and exercises. The teacher applies contrast and comparison between the grammar patterns of learners' first language and target one to explain the rule. In fact, explaining the new grammatical structures in the target language is carried on by translation. The learners are supposed to memorize the given rule. Language is used for comprehension the literature. Besides, translation is the way for learning the language. Also, Oral communication is not of great importance. In addition, written language is emphasized in comparison to spoken language. Besides, students learn the structure of their mother tongue. The teacher directs all the class activities since this method is teacher-centered and students are passive learners. The teacher chooses the activities. In addition, students are asked to memorize the rules and the new lexical items along with their meanings in their first language. Most of the time, there are "teacher -Student" interactions while "Student - Student" interactions occur rarely. The most common technique used for vocabulary teaching is the memorizing lists of vocabulary along with their equivalents in the learners' first language. Furthermore, texts from the target language literature are applied. The teacher may either use an authentic literary text or write the text. Structural syllabus i.e., the structure order starts from the easiest one. As far as speaking the target language is emphasized, classroom instructions are given in first language. Furthermore, one important way to test learners' progress is translation in their mother tongue. Also, "fill-in-the-blank" questions are used. To test vocabulary antonyms, Synonyms, and cognates are asked. Goals and objectives of this method are to make the learners familiar with their native language vocabulary and structure, to teach translation, to improve students' mental capacities using grammar exercises, and to understand literary texts in the target language. The teacher correct students' grammatical inaccuracy quickly, as mistakes are not to be tolerated.

Audio-lingual Method: In this method, teachers place much emphasis on practice of dialogues. Also, learning target language refers to acquiring habit. First, target language is listened to drilled, and then it is written. Learning in this method is based on the principles of Behaviourism and Habit Formation is necessary. To actualize it, the teachers use repetitions and drills in the classrooms. The basis of language is descriptive linguistics. Every language is considered as its own specific system. The system is made of a couple of different levels: morphological, phonological, and syntactic. Regarding skills, there is a natural order: listening, speaking, reading, and Writing. Oral skills and Everyday speech are important. 


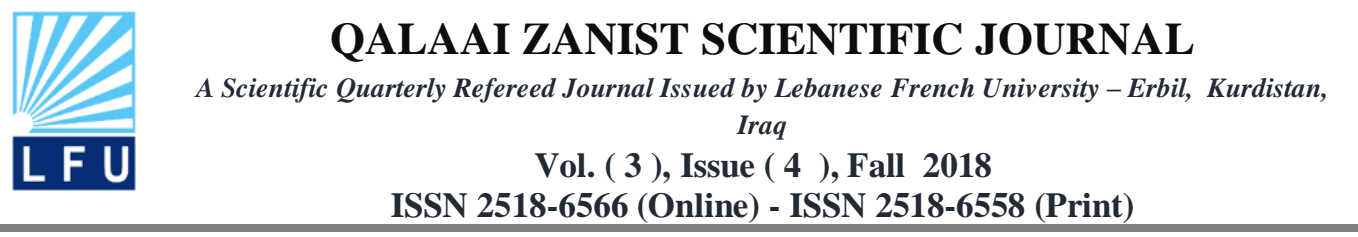

Perfect pronunciation is required. The teacher is like a leader in the class. S/he controls and directs the language behaviour of the students. Besides, s/he is supposed to be a good model of the target language for oral skills. Students are seen as imitators of the teacher or the native speakers in the listening sections. Regarding teaching vocabulary, meaning is taught in a direct way. The use of first language is prohibited since it may result incorrect habit formations. Vocabulary is taught through dialogues. In addition, objectives of this method are to make learners able to write and speak in the target language and to apply the language automatically without hesitating. Techniques which are used in this method by teachers are: multiple-slot substitution drill, single- slot substitution Drill, chain drill, mechanical drills, complete the dialogue, minimal pairs, dialogue memorisation, grammar Games and repetition drill.

The Oral Approach and Situational Language Teaching: This method, in the beginning, focuses on teaching spoken language. The introduction and practices of target-language points are done situationally. This approach is based on behavioristic view of learning a foreign language. The processes of learning are more important than the conditions. The processes of this approach are: receiving material or knowledge, repetition to make them fixed in memory and the use of them in real practice to become a personal skill. Mistakes are forbidden so that the teachers can avoid formation of bad habits. Also, a teacher first presents language orally, later on in written form. This approach focuses on lexical items and reading. As a matter of fact, mastery of a series of high-frequency words is thought to result in good reading skills. An analysis of situational tables, a classification of its prominent grammatical structures and English into sentence patterns, is believed to assist the students to internalize grammatical structural rules. According to this approach, a lesson starts with intonation and stress practice followed by a presentation and a revision of new material (mainly vocabulary or structures). Then the teacher deals with oral drilling and practice of the presented elements. At the end, the class ends with reading activity or written exercises.

The Structural Method: In this method, language is seen as a set of grammatical rules, which is supposed to be dealt with in a specific order one at a time (Larsen-Freeman, 1990). For example, present simple is learned before present continuous. This approach refers the arrangement of words in order to form a suitable pattern of a sentence. In this approach, the teacher teaches content words, which their selection is determined by their teachability, simplicity and usefulness. A suitable situation is to be created in order to build up a vocabulary of content 


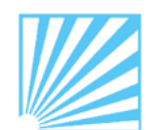

LF U

\section{QALAAI ZANIST SCIENTIFIC JOURNAL}

A Scientific Quarterly Refereed Journal Issued by Lebanese French University - Erbil, Kurdistan, Iraq

Vol. ( 3 ), Issue ( 4 ), Fall 2018

ISSN 2518-6566 (Online) - ISSN 2518-6558 (Print)

words, practice the structure, then to relate its meaning to it. The basis of the approach is the behaviorist theory. The teacher should be familiar with the structure and pattern of the target language to teach it. Language is seen as system of signals and structure so the learners can learn the target language very well if the teaching is coincide with its signals and structure in scientific way. The learners' activity is important in comparison with the teachers' activity. Learning a foreign language may be so easy if language is introduced into small structure and so effective if the language structure is demonstrated in the context of the learner's mother tongue.

Suggestopedia Method: The theory behind this method is that a learner is able to learn a language when there is no mental block. Dialogues accompany music and learners practice the target language playfully (Intarapanich, 2013). According to this method, Learners should get rid of the feelings that they cannot succeed and desuggestion of limitations is necessary. The teacher is seen as the authority. The students learn better if they receive the information through a reliable authority. They must respect and trust that authority. They also adopt a new identity to feel more secure. In addition, they do group work and pair work. In this method, the focus is on list of words that are to be learned and the meaning explanation is done through the students' native language. Also, grammar rules, which are taught explicitly, are explained in learners' native language. Furthermore, dialogues are applied along with their translations in students' native language. Evaluation is based on learners' performances in the classes. It is not conducted by formal tests since it may destroy the relaxed atmosphere. The objectives of this method are to accelerate the process of learning to use language for everyday communication. Since this method places emphasis on communication, the teacher does not correct errors immediately. When they happen, the teacher applies the correct form during the class later on because s/he does not want to threaten the relaxed atmosphere of the classes by immediate interference. In fact, the students' feelings are given a lot of attention and their self-confidence is of great importance.

Total Physical Response Method (TPR): In this method, teachers have students to respond to simple commands like "open the door" Besides, translation is not allowed during classes. Also, the emphasis is on aural comprehension. According to this method language learning is similar to the acquisition of first language. In the beginning, Learners listen, then oral production happens. Oral communication is crucial. the use of imperatives by the teacher can be useful for learning a lot of grammatical structures and vocabulary items. Besides, social life traditions and daily habits should be learned. At the start, the teacher is considered 


\section{QALAAI ZANIST SCIENTIFIC JOURNAL \\ A Scientific Quarterly Refereed Journal Issued by Lebanese French University - Erbil, Kurdistan, Iraq \\ L F U Vol. ( 3 ), Issue ( 4 ), Fall 2018 \\ ISSN 2518-6566 (Online) - ISSN 2518-6558 (Print)}

as the director of all learners' behaviour. At the end, the teacher is supposed to being directed. In regard to teaching vocabulary, it is introduced through applying imperatives. In other words, the teacher use verbs as the core and adverbs, adjectives, and nouns are introduced around the verbs. Concerning grammar, singleword chunks, Multi-word chunks are applied along with imperatives. In addition, tasks helping kinaesthetic learning, written texts, visuals, Objects around are used in the classroom. To evaluate the students, the teacher will realize immediately that they understand or not by watching their actions. Formal evaluations are done simply by commanding them to perform a set of actions. The objectives of the method are to help the learners to enjoy language learning and using.

Communicative Approach (CLT): This method emphasizes on functions such as suggesting, complaining and inviting. Its purpose is to prepare students for effective communication in different situations. The aim of teaching a target language is to develop communicative competence (Brown, 1987). Appropriate use of the language in social contexts is of great important and communicative competence should be obtained(Brown, 1987). This approach sees language as a system to express meaning. In other words, the primary use of language is for communication and interaction. Besides, the primary components of language are not its structural and grammatical features, but categories of communicative and functional meaning. One important aspect of learning language for communication is the use of Body language and non-verbal behavior, which is different from culture to culture. The teacher is a facilitator of the learners' learning and a manager of activities in the classroom. Regarding vocabulary, it is taught in the context. Meaning are be conveyed by models, using visual aids, real objects, and context. Concerning materials, the teacher uses those which are applied by native speakers in real life such as articles from newspapers or magazines, advertisements, songs, authentic materials, short stories. Communicative activities (information gap, opinion gap activities) are used to promote students' communication in classes. Also, task based activities are applied to increase the learners' involvement in the classroom. Furthermore, the teacher evaluates the learners' fluency and accuracy. The teacher may ask the students to write a letter to a friend in order to test their writing skill.

The Silent Way: In this method, the teacher is supposed to talk less so that the learner can be given an opportunity to be in control of his/her speaking. From the beginning, all four skills are thought with no use of the first language. This method is based on Cognitive Psychology and it is rule formation. Learning a 


\section{QALAAI ZANIST SCIENTIFIC JOURNAL \\ A Scientific Quarterly Refereed Journal Issued by Lebanese French University - Erbil, Kurdistan, Iraq \\ L F U Vol. ( 3 ), Issue ( 4 ), Fall 2018 \\ ISSN 2518-6566 (Online) - ISSN 2518-6558 (Print)}

Language has an order from the familiar to the new. Students are supposed to induce the rules from languages they deal with and examples, so 1 inductive earning is carried on. Language is seen as a means to express ideas, thoughts, feelings and perceptions. Cognitive Coding helps students to learn the language. Fidel Chart and Color rods are applied for cognitive coding. The teacher is like an engineer who makes learning easy. The teacher is familiar with what the learners already know and he/she determines the next step. The silent teacher gives the responsibility to the learners and helps them monitor themselves. In this method, the students can learn from each other. Lexical items are taught through word-charts and visual aids. Sound color charts to teaching pronunciation, Fidel Charts for sound spelling association and color rods for cognitive coding of grammatical structures. The teacher assesses the learners' learning all the time. S/he monitors them continuously. Objectives of this method are to enable the learners to apply the foreign language to express them and be independent. Errors are considered natural. Students' errors help the teachers to decide where further work is necessary. Furthermore, selfcorrection is essential for the learners to compare their own articulation with their progressing inner criteria. If students cannot self-correct, the teacher supplies the correct language but only as a last resort. Peer correction is also very common, but it should be in a co-operative manner. Besides, learners are encouraged to help each other in order to create a enjoyable and relaxed atmosphere.

Community Language Learning (CLL): To help learners eliminate psychological barriers to learning, teachers build a good relationship with their students (Intarapanich, 2013). In this method, the use of mother tongue is allowed. In this theory, the learners should feel secure in order to have a successful experience of learning. The teacher's attitude to learners, their' relations with each other and classroom atmosphere affect their feelings of security. The learners need quiet time for reflection to learn. The teacher reads a text for several times and the learners are to listen and relax for reflection. They even listen to their own voice for reflection. They should distinguish the differences from the similarities among foreign language forms through listening to the teacher and themselves carefully. In addition, they are to listen to find out whether what they say is different or similar to what their teacher says. In this method, Language is used for developing creative thinking and for communication. Language is seen as what you learn as well as what you share with other people. Students are to trust the teacher, the learning process and the others. Furthermore, being familiar with the target culture is considered as an important factor to succeed in communication. The teacher is like a counselor in the classroom. The teacher tries to eliminate the threatening barriers in the 


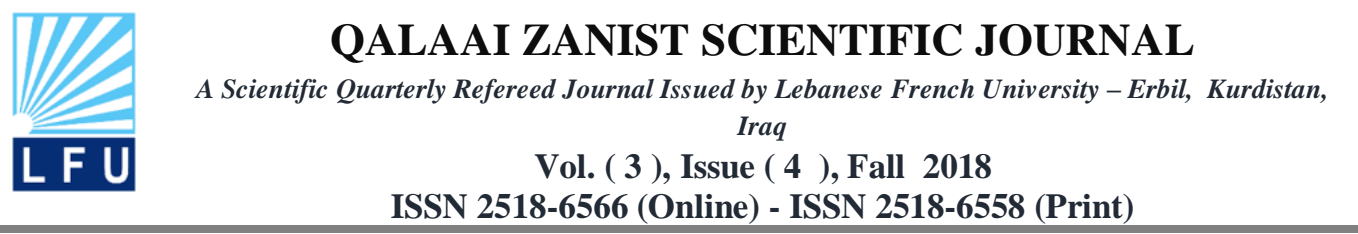

classroom. In the beginning, the students are dependent on their teacher. As they learn more, they become more and more independent. Concerning grammar, the analysis of large chunks are done by using first language. Having a textbook is necessary, so the teacher may develop the materials during the course. In fact, students' needs determine materials. For evaluation, the teacher makes the test and the learners are required to give an oral interview or write a paragraph.

Each approach/ method enjoys its own advantages and disadvantages. Teachers are those who decide which one or when to implement them in foreign language classrooms in regard to different situations.

\section{Methodology}

\subsection{Research Design}

This qualitative study was done at four public schools and four English Language Centers in Mahabad. It explored language teaching approaches, methods and strategies in English classrooms through interviews with teachers and their observations. For the study Jack Richards and Theodore Rogers's book "Approaches and Methods in Language Teaching" were used as a basis of taxonomy to indicate methods, which are used today.

\subsection{The selection of Participants}

The selection of schools and Centers was because of the accessibility of participants, schools and Centers at the time of the research. The study participants involve 8 teachers from selected schools and 4 teachers from the English Language Centers and the researcher as a non-participant observer. The school teachers were teaching senior high school students. Each participant's backgrounds were collected through an interview.

\subsection{Data Collection}

For the purpose of data collection, two qualitative research methods have been used; interview with 8 teachers of English from four different high schools and 4 teachers of English Language Centers and direct observation. During last two weeks of academic year in 2017, data was collected, i. e., 3 hour a week. The researcher attended the classes and observed the teachers' methods and strategies they used in the class. During observation, she as a non-participated observer wrote down all class activities in chronological order. After the last session of observation, 
teachers were asked to answer a list of questions asked at the guided interview, explain their teaching methods and strategies they use while teaching English and their perspective on teaching. In addition of the manual notes, the researcher used video and audio recordings, tools to obtain data, during interviews and six-hour class observation.

\subsection{Data Analysis}

To analyze the data obtained from recorded interviews and observations, the researcher listened to and considered all of them, and then transcribed them. When transcripts have been broken down into manageable sections, the researcher sorted them. The next stage of data analysis involves bringing similar categories together into broader themes. At the end, she determined the most common activities, tools and materials used in the class by the teachers.

\section{Findings and Discussion}

\subsection{Discussion of Observations in School Findings}

In the schools, most of the class activities were based on Grammar Translation method. The teachers translated the text in the textbooks. Teachers placed emphasis on rote learning of word lists. Also, they explained grammar elaborately. First, rules were presented, and then students asked to memorize them. They asked students to memorize specific number of vocabulary per day in English and give their Kurdish equivalent. Later on, they should give their own examples. To compare first language to the target language, new lexical and grammatical items in English were explained in Kurdish. There was very little attention to listening and speaking comprehension. As a matter of fact, they focused on syntax and morphology. The exercises also focused on translating from Kurdish to English and vice versa.

Choral drill and repetition, which teachers applied to teach students correct pronunciation of lexical items in the target Language, reflected the use of the Audiolingual Method by teachers.

\subsection{Discussion of Observations in English Language Centers' findings}

Lesson activities observed in the Centers, Intermediate level classes, revealed that the Audio-lingual Method (ALM) and the Communicative Language Teaching (CLT) were applied in the classes. Since the emphasis is on natural 


\section{QALAAI ZANIST SCIENTIFIC JOURNAL \\ A Scientific Quarterly Refereed Journal Issued by Lebanese French University - Erbil, Kurdistan, Iraq \\ L F U Vol. ( 3 ), Issue ( 4 ), Fall 2018 \\ ISSN 2518-6566 (Online) - ISSN 2518-6558 (Print)}

spoken language in the audio-lingual method, teachers presented vocabulary and grammar through dialogues, which enjoys a cultural context. In the first place, the teacher read the dialogue, and then it would be presented with a recording. Students were to repeat each line in chorus after the recording several times. Consequently, after memorizing the dialogue by students, the whole class took one role, then the teacher took the other, and also they changed parts. At the end, students practiced the dialogue in pairs, groups of three or so, then role played it in front of the class. Regarding Communicative Language Teaching, there were discussion and conversation lessons, role-plays and debates. The teachers sometimes asked students to choose a topic they like, and then they were asked to memorize it and say it by heart as a story over a specific time. Besides, teachers taught grammar within through communicative tasks. There was little teacher talk in the class. In regard to reading, students were asked to read the texts aloud while showing their emotions. The teachers asked questions about the content of the text. Consequently, they were asked to talk about the texts in pairs or in groups. In addition, the teachers were caring, active, adaptable, polite, and friendly.

\subsection{Discussions of Interviews with Teachers from schools}

Findings of the interviews with the teachers from high schools demonstrated that teaching had been done in Mahabad with simple tools like whiteboards and pictures with no overhead projector or CD/DVD players in the classes. The teachers believed that textbooks emphasize on grammatical structure and communication has been ignored. From their perspective, English classes in high schools are boring because a set of texts with comprehension questions along with grammatical points have been included in the textbooks. As a result, they have no choice but using Grammar-Translation Method.

\subsection{Discussions of Interviews with Teachers from English Language Centers}

Teaching English had been done with tools and materials such as whiteboards, worksheets, textbooks, flash cards, pictures, CD/DVD players and overhead projectors. Group-works, conversation, debates and role-plays were strategies to teach English in the classes. These strategies are considered as opportunities for the students to share ideas and communicate. The teachers in English Language Centers were well familiar with skills and were competent to teach English to intermediate learners applying various activities and strategies. 


\section{Conclusion}

Regarding senior high schools in Mahabad, Grammar Translation method and the Audio-lingual Method were used frequently in the English classes. Selected strategies and activities from these two methods were those observed most frequently in the classes. Concerning English Language Centers in Mahabad, the Audio-lingual Method (ALM) and the Communicative Language Teaching (CLT) were the dominant methods applied in English classes. Learning strategies and activities from these two methods and approaches were those observed mainly in the classrooms. Being compared with senior students of the high schools, reading aloud, group-work, pair-work, conversations, repetition drills, the spelling activities, role-plays and debates were definitely preferred in the classes of the English Language Centers. These activities helped students to use the language and communicate. Also, the teachers were friendly, adaptable, polite, and caring. Besides, they enjoyed abilities and skills to use a variety of activities. On the other hands, the teachers from schools translated the texts in the textbooks. The teachers placed emphasis on rote learning of word lists and explaining grammar elaborately. New lexical and grammatical items in English were explained in Kurdish. The teachers focused on syntax and morphology. Repetition drill the teachers applied to teach correct pronunciation of lexical items to students. Tools and materials such as whiteboards, worksheets, textbooks, flash cards, pi ctures, CD/DVD players and overhead projectors applied for learning and teaching English. The teachers claimed that they are not happy with the approach they have to use because of the textbooks. All in all, the observations and the interviews revealed that students of the English Language Centers can improve their English faster than the senior students in high schools of Mahabad. 


\section{QALAAI ZANIST SCIENTIFIC JOURNAL}

A Scientific Quarterly Refereed Journal Issued by Lebanese French University - Erbil, Kurdistan, Iraq

LF U

Vol. ( 3 ), Issue ( 4 ), Fall 2018

ISSN 2518-6566 (Online) - ISSN 2518-6558 (Print)

\section{References}

Akbari, Z. (2015). Current challenges in teaching/learning English for EFL learners: The case of junior high school and high school, Procedia - Social and Behavioral Sciences 199(2015), $394-401$

Ashari, N. \& Zarrin, N. (2014). Problems in Using Communicative Language Teaching in Iran and Possible solutions, Technical Journal of Engineering and Applied Sciences 4 (4), 257- 266

Behroozi, M. \& Amoozegar, A. (2014). Challenges to English language teachers of high school in Iran, Procedia - Social and Behavioural Sciences, 136(2014), 203 - 207.

Boran G. Methods and Approaches in Language Teaching in Brief. http://w3.gazi.edu.tr/ gboran/Boran\%20Yeni\%20WebEnglish/eltmethods .htm. 16/9/2010.

Brown, D. H. (1987). Principles of Language Learning and Teaching. New Jersey: Printice Hall Regents.

Intarapanich, C. (2013).Teaching Methods, Approaches and Strategies Found in EFL Classrooms: A Case Study in Lao PDR. Procedia - Social and Behavioral Sciences 88(2013), $306-311$

Larsen-Freeman, D. (1990). Teacher's handbook for the video series language teaching methods. Washington, DC: Office of English Language Programs Materials Branch, United States Department of State Washington.

Richards, J. Rodgers, T. (1989). Approaches and Methods in Language Teaching. New York: Cambridge University Press.

Willis, D. (1990). The lexical syllabus: A new approach to language learning. London: Collins ELT. 